\title{
LITERATURA LATINO-AMERICANA E NOVAS CARTOGRAFIAS (A PERSPECTIVA DOS ESCRITORES)
}

\author{
Ana Cecilla Olmos
}

Universidade de São Paulo

\section{Resumo}

Quando se deslocam para o território do ensaio, os escritores de ficção privilegiam a literatura como tema; desdobram o comentário de alguma leitura, sinalizam suas preferências literárias ou explicitam posições nos debates culturais. O ensaio apresenta-se como uma instância de indagação da própria prática de escritura em diálogo com o exercício da crítica literária, mas sem se identificar com suas formas institucionalizadas, dado que dissolve os limites conceituais dos saberes disciplinares na deriva de uma enunciação subjetiva que resiste qualquer forma de sistematicidade. Na sua liberalidade, o ensaio garante a possibilidade de interferir criticamente na ordem estabelecida do literário, reativando os debates culturais desde a perspectiva do escritor. Este trabalho aborda um conjunto de ensaios de narradores que se interrogam sobre as condições de possibilidade da literatura latino-americana no contexto globalizado das práticas de escritura do século XXI. Alheios ao exercício metódico de uma crítica literária que aporte as provas de uma suposta especificidade dessa literatura, os ensaios de Jorge Volpi, Juan Villoro e Sergio Chejfec oferecem-se como exercícios de imaginação que configuram cartografias críticas a qualquer perspectiva reducionista da diferença, propondo trânsitos extraterritoriais que liberam a palavra literária dos compromissos da representatividade.

\section{Abstract}

When moving to essay territory, fiction writers privilege the literature as the theme; they unfold some reading commentary, signaling their literary preferences or showing their positions on cultural debate. The essay presents itself as an instance of questioning their own writing practice in relation with the exercise of literary review, but without identification with its institutionalized ways, because it dissolves the limits of disciplinary knowledge concepts drifting to subjective enunciation that resists to any kind of systematized writing. In its freedom, the essay ensures the possibility to interfere critically in the established literary order, reactivating cultural debate from the writer perspective. This work deals with a set of narrator essays that question the conditions of the Latin American literature possibility in a globalized context of the writing practice in the $21^{\text {st }}$ century. Detached from the methodical exercise of literary review that gives proof of a supposed specificity to this kind of literature, the essays of Jorge Volpi, Juan Villoro and Sergio Chejfec are imagination exercises and configure critical cartography to any difference reduction perspective, proposing extraterritorial transits that free the literary word from representativeness commitment.

\author{
Palavras-chave \\ Literatura \\ latino-americana; \\ ensaio; \\ identidades \\ literárias; Juan \\ Villoro; Sergio \\ Chejfec; Jorge \\ Volpi.
}


felicidade existe em relação direta com a liberdade que nos é permitido exercer num determinado momento, assim sendo, o ensaio é o gênero literário mais feliz, explica César Aira. ${ }^{1}$ A afirmação do autor argentino não se limita a sinalizar a absoluta liberdade formal que caracteriza o ensaio, ela também sugere que é nessa forma discursiva que o escritor pode resgatar o prazer originário que traz a satisfação plena da pulsão que o impele à escritura. Noutras palavras, quando as convenções das formas literárias estreitam o campo de ação do escritor, o ensaio está sempre à disposição para oferecer a venturosa promessa de uma escritura liberada de qualquer condicionamento. Não é incomum, portanto, que os autores de ficção frequentem o ensaio como uma forma de recuperar a total disponibilidade de uma escritura que se desvencilha de qualquer determinação prévia e só responde ao arbítrio da subjetividade de quem escreve. Sabemos que a enunciação subjetiva que indaga uma experiência de mundo, o movimento aleatório e descentrado da reflexão e o caráter provisório de um saber que resiste às certezas conclusivas são os traços que caracterizam o ensaio. Desde sua origem moderna - a arrojada e sugestiva aventura de Montaigne - até os dias de hoje, a liberalidade do ensaio abriu espaço para uma escritura de deriva que dissolve a rigidez dos códigos retóricos, desestabiliza a ordem hierarquizada do conhecimento e renuncia a qualquer pretensão de verdade objetiva ao trazer a um primeiro plano o ato de explorar um tema estabelecendo uma relação intrínseca entre sujeito, linguagem e mundo.

Da inesgotável variedade de temas que podem ser abordados no ensaio, os autores de ficção privilegiam a literatura. Nessas páginas, os escritores podem desdobrar o comentário de um livro, explicitar as preferências literárias, manifestar as tomadas de posição nos debates culturais ou, inclusive, confessar, não sem uma

${ }^{1}$ César Aira, "El ensayo y su tema", in Boletín 9 del Centro de Estudios de Teoría y Crítica literaria, Rosario, Universidad Nacional de Rosario, 2001, p. 15. 
dose de perplexidade, os rituais do próprio processo criativo. Seja qual for o aspecto abordado, quando o tema é a literatura, o ensaio dos narradores se apresenta como uma instância de indagação que dialoga com o exercício da crítica literária, mas não se identifica plenamente com suas formas institucionalizadas, dado que dissolve os limites conceituais dos saberes filológicos na deriva de uma enunciação subjetiva que resiste qualquer forma de sistematicidade. Como explica Silvio Mattoni, ${ }^{2}$ ao se instalar nesse lugar de interferência, entre as impressões subjetivas e os domínios positivos do saber, o ensaio literário oferece a possibilidade de exercer uma crítica cultural que questiona a ordem do conhecimento e das formas discursivas de sua transmissão, reativando os conflitos e debates culturais sob a perspectiva particular do escritor.

Esse é o aspecto do ensaio dos narradores que me interessa destacar nesta oportunidade. O ensaio não apenas como a instância de adequação da escrita ao irredutível do sujeito, senão também, como a instância de uma enunciação subjetiva crítica à ordem institucionalizada do literário. Cabe lembrar, nesse sentido, o caráter corrosivo da mais íntima lei do ensaio que assinalara Adorno: a heresia. Uma lei que permeia a configuração textual do gênero, resistente às tipologias discursivas, ao passo que define a relação crítica que a enunciação ensaística estabelece com a ordem positiva do conhecimento. O ensaio dos escritores propõe-se, portanto, como uma instância em que a literatura pode refletir sobre si mesma, questionar as formas estabelecidas e delinear outras possibilidades para sua prática.

$\mathrm{Na}$ esteira desse pensamento, proponho comentar um conjunto de ensaios de escritores que se interrogam sobre a singularidade da literatura latino-americana no contexto globalizado das práticas de escritura do século XXI. O argentino Sergio Chejfec e os mexicanos Juan Villoro e Jorge Volpi, autores de ficção que com frequência se deslocam para o território liberado do ensaio, especulam acerca da inserção dessa literatura na geografia mundial, colocando, mais uma vez, a pergunta sobre o seu traço diferencial. ${ }^{3}$

A questão permeia o processo de constituição dessa literatura e, ao longo do tempo, capitalizou uma importante reflexão que tentou dar conta de uma especificidade atendendo à localização periférica da América Latina na cartografia moderna. Com efeito, a singularidade dessa literatura configurou-se num movimento ambivalente entre as inclinações universalistas que a incorporam à cultura ocidental e as resistências localistas que lhe permitem inscrever uma diferença, vale dizer, num entre-lugar cultural que as abordagens teóricas do século XX, cientes das relações de dominação da geopolítica moderna, objetivaram em metáforas episte-

2 Silvio Mattoni, Las formas del ensayo en la Argentina de los años 50, Córdoba, Ed. Universitas, 2003, p. 22-3.

3 Serão considerados os seguintes ensaios: de Juan Villoro, "De iguanas y dinosaurios. América latina como utopía del atraso", in Efectos personales, Barcelona, Anagrama, 2001, p. 107-115; e Idem, "Itinerarios extraterritoriales", in De eso se trata. Ensayos literarios, Barcelona, Anagrama, 2007, p. 172-187; de Jorge Volpi, "La obsesión latinoamericana", in Mentiras piadosas, Madrid, Páginas de Espuma, 2008, p. 143-154; de Sergio Chejfec, "La dispersión. Sobre el futuro de la literatura como contigüidad", in El punto vacilante. Literatura, ideas y mundo privado, Buenos Aires, Norma Editorial, 2005, p. 27-33. 
mológicas tais como a mestiçagem, o hibridismo, a heterogeneidade, a transculturação. O tema, portanto, não comporta novidade alguma, no entanto, a insistência na pergunta ganha pertinência ao considerar a configuração da cartografia mundial das últimas décadas que, atrelada aos processos globalizadores do capitalismo tardio, traçou uma rede transnacional de intercâmbios culturais que parece desestabilizar a demarcação de fronteiras e suas referências identitárias.

Esse rápido comentário permite assinalar que os ensaios de Villoro, Volpi e Chejfec debruçam-se sobre um tema que possui uma trajetória relevante e que, ainda hoje, convoca debates instigantes em torno das articulações literárias do mapa mundial. Com a liberdade que define o gênero, eles retomam a questão para abordá-la desde as perspectivas subjetivas de suas próprias experiências de escritura. Não se trata, portanto, de rigorosas abordagens teóricas que analisam a condição periférica duma literatura atravessada, desde suas origens, por conflitantes relações de domínio e subalternidade, menos ainda de eufóricos discursos localistas que encerram a literatura na defesa de abstrações identitárias; esses ensaios são, antes, exercícios de imaginação que colocam a pergunta sobre o lugar da literatura latino-americana no mundo, não para se enclausurar na positividade de respostas certas e acabadas, senão para interferir criticamente na ordem institucionalizada do literário e socavar qualquer tentativa de definição de uma especificidade que esclerose as escrituras na repetição de fórmulas definidas de antemão.

É interessante lembrar que essa posição crítica marcou o início da trajetória desses escritores quando, por volta dos anos 1990, apelaram ao manifesto como estratégia de diferenciação no âmbito literário. Refiro-me ao manifesto do grupo Shanghai do qual participou Sergio Chejfec, junto de outros autores argentinos, em 1987, e ao manifesto Crack que alguns escritores mexicanos, dentre os quais se encontrava Jorge Volpi, lançaram em $1996 .{ }^{4}$ Em ambos os casos, tratava-se de uma recusa veemente de todo princípio estético que restringisse as condições de possibilidade da literatura à representação de uma identidade nacional ou continental. Noutras palavras, recusava-se uma tradição literária que estabelecia uma relação intrínseca com a representatividade local e que, nas décadas precedentes, havia atingido seu ápice com as premissas do realismo mágico que a voracidade do mercado estimulava. Certamente, a opção pelo manifesto favorecia a expressão do gesto iconoclasta dos novos escritores, ao passo que delimitava uma posição singular para suas escrituras; no entanto, o caráter coletivo dessa intervenção cultural, assim como o impulso propositivo que ela sempre comporta, parecia ir de encontro à negativa a definir o exercício da literatura em função

${ }^{4}$ Por trás da redação do manifesto do Grupo Shanghai (1987) encontravam-se os escritores argentinos Martín Caparrós, Jorge Dório, Alan Pauls, Ricardo Ibarlucía, Luis Chitarroni, Sergio Chejfec, Daniel Guebel e Carlos Eduardo Feiling. Os escritores mexicanos Jorge Volpi, Ignacio Padilla, Eloy Urroz, Miguel Angel Palou e Ricardo Chaves Castañeda subscreveram o Manifesto Crack (1996). Juan Villoro não fez parte desse grupo, no entanto, suas posições com relação à prática literária na América latina apresentadas nos ensaios não divergem substancialmente das expostas nesse manifesto. A mesma posição crítica com relação à literatura das décadas precedentes pode ser reconhecida no prólogo a McOndo, uma antologia de contos latino-americanos publicada, em 1996, pelos escritores chilenos Alberto Fuguet e Sergio Gómez. 
de valores ligados a uma representatividade. De fato, essa estratégia de confronto grupal logo evidenciou a debilidade de sua incidência e foi rapidamente abandonada para dar lugar à expressão incondicionada de uma diversidade de escrituras. ${ }^{5}$ Sem aprofundar na questão, é possível pensar que, esgotada a provocação coletiva e performática do manifesto, a forma discursiva do ensaio apresentou-se como uma opção mais ajustada para a expressão de subjetividades que desconfiam das definições programáticas do literário. Avessa a proposições e conclusões, a forma do ensaio oferece a esses escritores o lugar de uma voz, um lugar para a própria voz, a partir do qual eles podem interrogar as suas práticas e, num duplo movimento, intervir criticamente na ordem estabelecida do literário, sem deixar de explorar a singularidade intransitiva de suas poéticas.

\section{"A pátria é um sítio de extravio" (Juan Villoro)}

Com frequência, é a evocação de uma vivência pessoal a que, em estreita relação com o tema a ser abordado, impulsiona o processo de escritura nos ensaios de Villoro. Esse recurso discursivo acentua a enunciação subjetiva que define o gênero e aproxima essa forma textual da autobiografia, porém sem que ela assuma as feições de um relato de vida. É o caso do ensaio "Iguanas y dinosaurios. América latina como utopía del atraso", no qual o autor desdobra uma reflexão acerca dos estereótipos que as perspectivas estrangeiras projetam sobre a literatura latino-americana em demanda de uma representatividade local. O escritor relata que seus primeiros anos escolares transcorreram numa instituição alemã da cidade do México que destinava vagas para alunos nativos como parte de uma política de integração cultural. Após a perplexidade inicial que provocou o fato de ser alfabetizado em alemão, a experiência delimitou um lugar cultural que, segundo Villoro, seria decisivo na hora de definir a sua posição de escritor no mundo. "Esta educación extravagante" - diz o autor - "tuvo dos resultados: nada me gusta tanto como el español y detesto cualquier idea reductora de la identidad nacional". ${ }^{6}$

Em relação com essas afirmações, Villoro recria com simpáticos traços de humor aqueles anos da escola que o instalaram prematuramente na fixidez de uma alteridade cultural que seus professores prefiguravam:

\footnotetext{
${ }^{5}$ Se considerarmos a posição de Josefina Ludmer quando especula acerca de um final do ciclo da autonomia literária na atualidade, seria possível pensar que, nos anos 1990, esse recurso ao manifesto estaria condenado ao anacronismo, dado que, para essa época, as posições estético-políticas do período anterior (as décadas de 1960 e 1970) teriam sido neutralizadas. A autora argumenta que, no processo de perda da autonomia literária, se dissolvem as classificações tradicionais (realismo e vanguarda, literatura pura e literatura social, literatura urbana e literatura rural etc.) e, com elas, "parecen terminarse los enfrentamientos entre escritores y corrientes; es el fin de las luchas por el poder en el interior de la literatura. El fin del 'campo' de Bourdieu, que supone la autonomía de la esfera o el pensamiento de las esferas. Porque se borran las identidades literarias, que también eran identidades políticas. Y entonces puede verse claramente que esas formas, clasificaciones, identidades, divisiones y guerras solo podían funcionar en una literatura concebida como esfera autónoma o como campo. Porque lo que dramatizaban era la lucha por el poder literario y por la definición del poder de la literatura". Cf. Josefina Ludmer, Aquí América Latina. Una especulación, Buenos Aires, Eterna Cadencia, 2010, p. 153-154.

6 Villoro, "Iguanas y dinosaurios. América latina como utopía del atraso", op. cit., p. 107.
} 
Puesto que yo representaba la otredad, nada podía beneficiarme tanto como las rarezas. Mientras más picaran nuestros chiles, mejor sonarían mis informes. Los maestros gozaban con las truculencias de su país de adopción. Su demanda de exotismo me hizo describir una patria exagerada, donde mis primos desayunaban tequila con pólvora, mis tías se encajaban espinas de agave para castigar sus malos pensamientos y sangraban por la casa, como si posaran para Frida Kahlo, mi abuelo era fusilado en la revolución y por todo legado dejaba el ojo de vidrio con el que yo jugaba a las canicas. ${ }^{7}$

O relato do papel desempenhado na escola é uma irônica impostação pela qual o autor coloca em evidencia os condicionamentos que o cartesianismo das perspectivas europeias impõe a uma identidade mexicana caracterizada pelo excesso. Villoro afirma ter esgotado o repertório de estranhezas que definiriam a tipicidade nacional de sua literatura nessa experiência escolar de precoce autor de narrativas mágico-realistas. Paradoxalmente, foram essas demandas de exotismo de seus professores as que lhe ensinaram que só uma posição crítica ante elas pode garantir a liberdade da invenção literária.

Não obstante, Villoro adverte que colocar em crise o eurocentrismo da cartografia moderna, que limita as possibilidades da literatura a uma representação do território de origem do escritor, não parece ser suficiente para eliminar o risco dos fundamentalismos folclóricos. Segundo o autor, as novas disposições culturais da geografia global, que dissolvem fronteiras e estimulam o fluxo de intercâmbios, insistiriam igualmente nas demandas de exotismo, agora apresentadas sob o tópico da diversidade. Nesse novo contexto, diz Villoro: "El aborigen no es un ser inferior, sino distinto. Sin embargo, está obligado a ser distinto en forma unívoca, como custodio y garante de la alteridad". ${ }^{8}$ Nesse sentido, o escritor adverte que os multiculturalismos contemporâneos, ao acolher de forma des-hierarquizada as particularidades identitárias, neutralizariam a dimensão política da diferença e favoreceriam a continuidade de processos de subalternização, dado que, nas suas palavras,

estamos ante un colonialismo de nuevo cuño, que no depende del dominio del espacio sino del tiempo. En el parque de atracciones latinoamericano, el pasado no es un componente histórico sino una determinación del presente. Anclados, fijos en su identidad, nuestros países surten de antiguallas a un continente que se reserva para sí los usos de la modernidad y del futuro. ${ }^{9}$

Em um ensaio posterior, "Itinerarios extraterritoriales", Villoro retoma essa reflexão e assinala que as cartografias culturais da globalização, assim como os discursos pós-coloniais que tentam explicá-las teriam substituído a sobreinterpretação moderna da alteridade pela sobrecompreensão de sua diferença. ${ }^{10}$ Nessa linha de pensamento, o autor sugere que inclusive o hibridismo cultural, que algumas perspectivas teóricas reivindicam para a alteridade latino-americana, deveria ser considerado com cautela. A ideia do híbrido pensa a identidade como processo e já não em termos de essência, isto é, desarraiga as culturas da referência local para incorporá-las a uma zona de transição e permanente mudança. Villoro reconhece essa potencialidade crítica da ideia desde que ela não vire moda e se limite

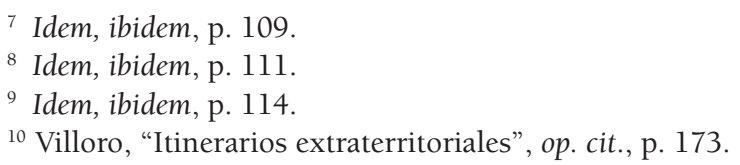


a substituir o representativo e o genuíno pelo "combinado". Com marcada ironia, o escritor observa que, no caso de a noção de hibridismo cultural se tornar dominante, a tarefa crítica "olvidará a los burros de siempre para concentrarse en exclusiva en los burros posmodernos, pintados de cebra en Tijuana para que los turistas se retraten junto a ellos". ${ }^{11}$

Nem estereótipos nacionalistas, nem multiculturalismos anódinos, nem hibridismos esterilizantes, a posição crítica de Villoro recupera para a literatura uma condição extraterritorial que a libera de qualquer compromisso de representatividade local. Instalada na cartografia imaginária que desenham os trânsitos do autor por diferentes línguas, culturas e tradições, a literatura estabelece conexões com a cultura local, porém, diz Villoro, desde uma perspectiva oblíqua, "exiliada" da realidade a qual pertence. Contra a fixidez identitária que condena a literatura ao passado e a uma reiteração infinita do mesmo, o escritor propõe a ideia de que " $L a$ patria es un sitio de extravio, un horizonte escapadizo, siempre extraño, que solo entrega una promesa: mañana será distinto". ${ }^{12}$

\section{"A ficção literária não conhece fronteiras" (Jorge Volpi)}

Se o traço autobiográfico pauta, com frequência, o ensaio literário de Villoro, o jogo inventivo alimenta a escrita ensaística de Jorge Volpi numa instigante atualização dos textos híbridos de Borges. "La obsesión latinoamericana" é um bom exemplo dessa estratégia do discurso que imbrica a reflexão subjetiva do ensaio com a invenção especulativa da ficção. O futuro da literatura da América Latina é o tema desse ensaio e, como ponto de partida para sua abordagem, Volpi imagina um estudo crítico realizado por Ignatius H Berry, um catedrático de Hispanic and Chicana Literature da Universidade Estadual de Dakota do Norte. O hipotético artigo intitula-se "Cincuenta años de literatura latinoamericana 2005-2055. Un canon imposible" e teria sido publicado na revista $\mathrm{Im} /$ positions em junho de 2055. Volpi apela aqui ao conhecido recurso borgiano da referência bibliográfica falsa que desestabiliza os limites entre o real e o imaginado; no entanto, ao ser deslocado para o futuro, o dado bibliográfico assume abertamente sua condição imaginária.

O estudo de Berry, que Volpi "transcreve" textualmente, é uma divertida paródia do discurso acadêmico que exacerba, até a irrisão, as pretensões de rigor analítico das perspectivas críticas universitárias. Berry indaga as causas que teriam levado a uma significativa perda de qualidade da literatura latino-americana após o desaparecimento de Borges e dos grandes narradores do boom. Segundo o catedrático, o abandono das perspectivas nacionais foi a principal causa dessa desvalorização literária; abandono que se evidencia, sobretudo, na deslavada língua global, abstraída de localismos, que permeia a narrativa do período estudado, de 2005 a 2055. Num desalentado diagnóstico, Berry afirma:

A partir de los noventa, numerosos escritores latinoamericanos se rebelaron, torpemente, contra sus orígenes. Nacidos en los sesenta, no habían sufrido las convulsiones ideológicas que azotaron

\footnotetext{
${ }^{11}$ Idem, ibidem, p. 177.

${ }^{12}$ Idem, ibidem, p. 179.
} 
a sus predecesores y tal vez por ello no se involucraron con los conflictos de sus países. Su desarraigo fue tan notorio que al leer sus obras resulta imposible reconocer sus nacionalidades; el hecho de ser colombianos, mexicanos o argentinos se volvió en ellos un dato anecdótico, un apunte en su currículo, en vez de una referencia central. ${ }^{13}$

Para o suposto crítico americano, a perda da nacionalidade como "referência central" levou a uma destruição dos fundamentos naturais da literatura latino-americana, a qual se dispersou numa multiplicidade de tendências, todas alheias a um propósito de representatividade local, tornando impossível a organização de um cânone. Inclusive, acrescenta Berry, essa situação coloca em risco o trabalho dos especialistas que, em poucos anos, vão transitar como "espectros rancorosos e adormecidos" pelos desmantelados departamentos de estudos hispânicos de suas universidades.

A paródia é mordaz. O critério da representatividade local domina a perspectiva crítica de Berry que, como explica Volpi, insiste em demandar da literatura latino-americana uma singularidade local, em vez de considerá-la uma variante da tradição ocidental. A relação com Borges é inevitável. Berry sustenta as mesmas ideias de Carlos Argentino Daneri, a personagem de "El Aleph", porém, em 2055, um século depois. Segundo Volpi, o discurso crítico americano e europeu atual, parodiado no artigo fictício de Berry, não estaria isento desse anacronismo. A obsessão latino-americana retornaria nos dias de hoje sob as vestes das perspectivas dos estudos pós-coloniais, igualmente devotados à recuperação de uma singularidade cultural. Nesse sentido, Volpi afirma:

Azotados por una especie de complejo de culpa histórico, consideran que Occidente debe abandonar sus actitudes coloniales y descubrir los aspectos soterrados u olvidados de sus antiguos súbditos. La premisa básica es el relativismo cultural: dado que ninguna civilización es superior a las otras, buscan frenar la expansión de la cultura occidental en el mundo para rescatar las peculiaridades de las naciones tercermundistas. Tres siglos de explotar a las otras culturas ahora se empeñan en rescatar los auténticos valores de los otros. ${ }^{14}$

A posição crítica de Volpi não visa desmontar apenas os pressupostos teóricos das perspectivas pós-coloniais que, embora resgatem as diferenças, nas suas versões pasteurizadas despojam as relações culturais das conflitantes dimensões éticas e políticas. O autor vai além e procura assinalar a insuficiência dessas perspectivas para pensar a literatura latino-americana. Obstinadas em reconhecer na literatura do continente uma autenticidade cultural, essas perspectivas críticas reatualizam as tensões entre localismos e cosmopolitismos da cartografia moderna, escamoteando estrategicamente o fato de que, desde o século XVI, os escritores latino-americanos se pensam a si mesmos como parte da cultura ocidental. No extremo oposto do discurso crítico de Berry, Volpi afirma que, "La ficción literaria no conoce fronteras: si ello es visto como un triunfo de la globalización y del mercado es porque no se comprende la naturaleza abierta de la literatura". ${ }^{15}$

\footnotetext{
${ }^{13}$ Volpi, "La obsesión latinoamericana", op. cit., p. 143.

${ }^{14}$ Idem, ibidem, p. 149.

${ }^{15}$ Idem, ibidem, p. 153.
} 


\section{"A narrativa como culto periférico" (Sergio Chejfec)}

Se a configuração textual do ensaio resiste às tipologias discursivas, não porque negue suas formas, senão porque explora seus domínios (o autobiográfico em Villoro, o relato fictício em Volpi), seria contraditório falar numa forma depurada do gênero. No entanto, os ensaios que Chejfec reúne em seu livro El punto vacilante aproximam-se dessa ideia. Na apresentação do volume, ele explica que o título assinala uma atitude de leitura em particular, aquela que "sin abandonar las evidencias, se reconoce en las vacilaciones". ${ }^{16}$ Uma forma de definir a atitude do ensaísta, poderíamos dizer, que se abre a uma experiência de mundo e, na sua indagação, evita a clausura das respostas definitivas.

Em "La dispersión. Sobre la literatura del futuro como contigüidad", um dos ensaios do livro, Chejfec tenta responder à pergunta sobre as condições de possibilidade da literatura latino-americana no século XXI. Escrito em 1996, o ensaio convoca a referência a Ítalo Calvino e suas propostas para o "próximo" milênio como ponto de partida para pensar tanto a ideia do futuro na literatura quanto a ideia de um futuro da literatura.

Segundo o escritor argentino, a noção de proximidade, no sentido cronológico de iminência, não existe na ficção, dado que o narrador trabalha com essa noção num sentido espacial, como contiguidade. Uma prova disso, comenta o autor, são as estratégias que se utilizam na hora de falar do novo milênio: alude-se ao futuro como um território vizinho, próximo do espaço que nossas consciências habitam no presente, ao qual nem sequer se lhe atribuem mudanças radicais. "El porvenir" - enfatiza Chejfec - "es un locus de negatividad, todo el futuro está en el mismo sitio, es un mero paso al costado, o una desviación desde donde observamos como extranjeros nuestro lugar". ${ }^{17}$ A ideia de futuro na literatura, portanto, supõe a invenção de um espaço alternativo, um território conjetural, que o narrador imagina a partir do passado e do presente.

Se na ficção o futuro é um deslocamento espacial, talvez seja a imagem da página em branco, afirma Chejfec, a que melhor metaforize a ideia de um futuro da literatura. A página em branco não como a imagem da potencialidade de sentidos tão explorada na poesia, senão como a espacialização do trabalho artesanal da escrita. De fato, explica Chejfec, a página está sempre disponível, junto do escritor, como um "espaço alterno e secundário", ou seja, como um tempo deslocado. Ele sugere pensar a literatura latino-americana do século XXI a partir dessa imagem do deslocamento inerente à existência da página, vale dizer, o futuro da literatura da América Latina como um deslocamento espacial que evite a representação direta do próprio lugar e se deslize em direção de territórios próximos, derrubando fronteiras, isto é:

La narrativa como culto periférico. Por ejemplo, una literatura desplazada hacia los países linderos. Argentinos escribiendo sobre Chile, venezolanos sobre Guyana, brasileños sobre Uruguay, chilenos sobre Perú, mexicanos sobre Guatemala. O, para despojarla de connotaciones

${ }^{16}$ Chejfec, "La dispersión. Sobre el futuro de la literatura como contigüidad", op. cit., p. 11.

${ }^{17} \mathrm{Idem}$, ibidem, p. 29. 
nacionales, entrerrianos escribiendo sobre Corrientes, merideños sobre Trujillo, paulistas sobre Rio Grande, tabasqueños sobre Chiapas. Ello significaría el futuro literario convertido en realidad $y$ verdad a la vez. ${ }^{18}$

Imaginar o futuro como deslocamento, como "dispersão", supõe desestabilizar a relação que a literatura estabelece com o lugar de origem do escritor e dissolver esse vínculo tantas vezes naturalizado em termos de valor estético. Liberada da âncora que a sujeita à representação local, a literatura pode transitar por fronteiras linguísticas, literárias e culturais e configurar novas cartografias que, como sugerem esses escritores, assumam uma perspectiva exterior que recuse as devoções locais. A perspectiva exterior da própria literatura, poderíamos dizer, se for pensada em termos de modernidade estética.

Ao abordar o tema da singularidade da literatura latino-americana, esses escritores não limitam seus ensaios ao exercício metódico de uma crítica literária que, circunscrita ao passado, aporte provas de uma suposta especificidade. Pelo contrário, eles apelam ao recurso retórico da inventio como uma estratégia discursiva instigante que, como explica Edward Said, ${ }^{19}$ permite expor relações que de outro modo permaneceriam ocultas atrás da inconsciência ou da rotina. Dessa forma, eles transformam seus ensaios em exercícios de imaginação que conjeturam cartografias críticas em diálogo com processos dinâmicos de ressignificação cultural. ${ }^{20}$

Não obstante, cabe assinalar que nos ensaios comentados ecoam as ideias de outros escritores que, em décadas anteriores, demandaram a mesma disponibilidade estética para a literatura na América latina. As leituras de Una literatura sin atributos de Juan José Saer e de El escritor argentino y la tradición de Jorge Luis Borges são óbvias, nem precisam ser mencionadas. Além delas, ecoam também as páginas de escritores como Alfonso Reyes ou Pedro Henríquez Ureña que, nos anos 1920 e 1930, advogaram pelo trânsito liberado da palavra literária. Esse percurso retrospectivo não neutraliza a posição crítica de Villoro, Volpi e Chejfec, pelo contrário, permite pensar, como diz Mattoni, ${ }^{21}$ que a heresia pode ser uma forma de ler a tradição e não sua negação inocentemente futurista.

${ }^{18}$ Idem, ibidem, p. 33.

${ }^{19}$ Edward Said, El mundo, el texto y el crítico, trad. Ricardo García Pérez, Buenos Aires, Debate, 2004, p. 76-77.

${ }^{20}$ Josefina Ludmer (op. cit., p. 162-164) afirma que a narrativa latino-americana dos anos 1990 instalou vozes antipatrióticas que delimitam uma posição exterior/interior da literatura com relação ao território nacional. Ela analisa um conjunto de narrativas do período e suas afirmações dizem respeito às vozes de narradores e personagens fictícios que se posicionariam num espaço linguístico interior à América Latina, porém num espaço intelectual exterior a ela. Esses narradores e personagens contemplam o território nacional desde o primeiro mundo, porém dizem-no com sotaque do interior do continente. Segundo Ludmer, essa posição exterior/interior acompanharia a transformação estrutural da relação Estado/Nação dos anos 1990 e sua reformulação nos anos 2000. Ainda que a ideia de uma literatura que transite entre fronteiras, segundo propõem esses ensaístas, se aproxime da noção de uma posição exterior/interior da literatura com relação ao território nacional, não pode ser pensada nos termos propostos por Ludmer, dado que a exterioridade nesses casos não seria a do primeiro mundo, representada nos discursos teóricos e críticos americanos e europeus. Pelo contrário, seria a perspectiva exterior de outras culturas periféricas ou, desde uma modernidade artística, a da própria literatura.

${ }^{21}$ Mattoni, Las formas del ensayo en la Argentina de los años 50, op. cit., p. 36. 